Motrivivência Ano XX, No 30, P. 185-196 Jun./2008

\title{
A produção do conhecimento das Universidades e a realidade escolar: uma análise crítica sobre o modelo atual de sociedade
}

\section{The production of knowledge in the Universities and the school reality: a critical analysis of the current model of society}

\author{
Angélica Caetano' \\ Andrize Romires Costa ${ }^{2}$ \\ Soraụa Corrêa Domingues ${ }^{3}$
}

\begin{abstract}
Resumo
Abstract

O presente artigo se propõe discutir a This article aims to discuss the current forma de produção de conhecimento nas Universidades e os reflexos desta na sociedade, especificamente, na escola. A Universidade, grande produtora de conhecimento, ao se tornar uma organização social e não uma instituição social acaba elegendo características vitais no processo de produção do saber, como exemplo, a estrutura de avaliação quantitativa das publicações científicas. Tais análises contribuíram para a compreensão knowledge production in Universities and its reflections on society, specifically, at school. The University, a major producer of knowledge, becoming a social organization instead of a social institution has elected vital characteristics in the production of knowledge, for example, the structure of quantitative assessment of scientific publications. These reviews have contributed to the understanding that this science is considered not socially
\end{abstract}

1 Mestranda em Educação Física na Universidade Federal de Santa Catarina

2 Mestranda em Educação Física na Universidade Federal de Santa Catarina

3 Doutoranda em Educação Física na Universidade Federal de Santa Catarina 
de uma ciência pouco relevante socialmente e para o entendimento de uma prática pedagógica pouco transformadora, principalmente quando este conteúdo científico não chega às Escolas ou não está direcionado a mudanças nas Escolas.

Palavras Chaves: Universidade; Produção de Conhecimento; Escola. relevant and the understanding of a little transformative pedagogical practice, especially when this scientific content does not reach the schools or is not targeted to changing schools.

Keywords: University; Knowledge production; School.

\section{Apresentação}

A construção deste artigo ocorreu a partir da reflexão promovida durante a realização da disciplina: Seminário Avançado de Investigação Pedagógica em Educação Física, no curso Mestrado/Doutorado de PósGraduação em Educação Física da UFSC. Busca debater a produção de conhecimento, aspirada pelo modelo "Capes ${ }^{4}$ de avaliação" ${ }^{5}$, a partir da análise crítica. Esse sistema vem sendo questionado não somente pela sua relevância e qualidade, mas também, pela distância entre o que é produzido nas Universidades e sua expansão para todos os envolvidos no mundo do trabalho pedagógico, ou seja, aqueles que se encontram na realidade da prática pedagógica. Para desenvolver este texto nos questionamos sobre quatro pontos:
A forma de organização acadêmica possibilita o desenvolvimento de estudos e pesquisas sobre a realidade escolar? Este conhecimento produzido nas Universidades do Brasil chega à Escola? Os professores e toda a realidade escolar são muitas vezes objetos de pesquisa científica, mas, eles têm acesso aos seus resultados? Esse conhecimento científico tem contribuído para responder às demandas sociais?

Refletindo sobre essas questões, precisamos entender e perceber, antes de tudo, a essência da Universidade e de Sociedade historicamente produzido; como ocorre a produção do conhecimento, o fazer ciência e sua transformação histórica; o que vem ocorrendo com o conhecimento científico produzido; quais vêm sendo os objetivos e quais deveriam ser estes.

4 Coordenação de Aperfeiçoamento de Pessoal de Nível Superior.

5 Denominamos este sistema como o regente de todas as Pós-graduações do Brasil. Ver termo utilizado em Bianchetti (2009). 


\section{Aproximações teóricas}

Atualmente, o modelo capitalista estrutura a vida com uma lógica problemática no que diz respeito à condição social, cujas conseqüências são imensuráveis, tais quais: trabalhadores mais produtivos a um menor custo, matéria - prima barata, mínimo de regulamentação trabalhista, busca da fragmentação das instâncias sociais que lutam pelo povo, entre outros. Toda essa imposição capitalista, unida a agentes financiadores internacionais e a burguesia reflete em nós em cada vez mais precários serviços públicos como Saúde, Educação e Lazer.

A lógica de organização da sociedade capitalista nos coloca imersos no mundo imaginário do consumo enfatizado pela mídia, por isso apesar de sermos sujeitos históricos, muitas vezes não percebemos como o processo de auto-regulação do capitalismo, principalmente em períodos de superação de crise, vem abordando temas sociais, tais como: a problemática ambiental, o narcotráfico, a prostituição, enfim, todas as questões que movimentam a atual economia e articulam a organização social. De acordo com Taffarel (2007), esses fatores citados acima, não assinalam o caminho para uma sociedade pós-capitalista, mas ao contrário, evidenciam o caminho acelerado à barbárie, ao superimperialismo.
Alguns desses impactos estão presentes na Universidade pública com o objetivo de formar em diversas áreas, pesquisadores e profissionais, ela sempre foi a unidade da formação e da produção do conhecimento. Esse conhecimento deve ser transformador, na medida em que uma das funções da Universidade é atender a demanda social, e considerando que a atual sociedade se organiza de forma a desfavorecer a vida, ou a sobrevivência da maioria, entendemos, então, que a busca por soluções que venham a superar essa atual organização deve partir de propostas científicas, que respondam às problemáticas da maior parte desta sociedade. Associada ao argumento da necessidade social, também lembramos que a Universidade se sustenta pelo pagamento compulsório de impostos dos cidadãos e que, por tanto, a produção do conhecimento deveria estar beneficiando seus contribuintes. Ao percebermos que há problemas a serem superados, que a Universidade é autônoma e considerando a ciência fundamental para estruturação econômica e social, entendemos a Universidade como instituição que deve fomentar a transformação social.

Por isso, concordamos com Chauí (2003), quando ela afirma que a Universidade vem deixando de ser unicamente uma instituição social 
diferenciada e definida por certa autonomia dando espaço ao modelo de organização social. Enquanto instituição social, ela pode relacionar-se com a sociedade e o Estado, de maneira conflituosa, justamente por não ser um reflexo deles e por subsidiar contraposições em relação às maneiras como a sociedade de classe e o Estado reforçam a divisão e a exclusão social.

\begin{abstract}
A Universidade pública sempre foi uma instituição social, isto é, uma ação social, uma prática social fundada no reconhecimento público de sua legitimidade e de suas atribuições, num princípio de diferenciação, Ihe confere autonomia perante outras instituições sociais, e estruturada por ordenamentos, regras, normas e valores de reconhecimento e legitimidade internos a ela (CHAUÍ, 2003, p. 5).
\end{abstract}

Porém, hoje, a Universidade, com características de organização social, já não tem mais esse caráter, e sim, o fomento de produção de conhecimento que vai ao encontro com a demanda capitalista. O conflito já não é existente, e sim o consenso entre o Estado, sociedade e Universidade, nos fazendo pensar a idéia do mercado capitalista, e como esta influencia toda a organização da sociedade mundial, inclusive a sociedade acadêmica, enfatizando a relação entre capital e trabalho e como estes vem correspondendo aos projetos de escolarização.

Cogiolla apud Taffarel (2007) nos coloca a seguinte explanação:

[...] A construção do saber científico busca ampliar os horizontes de liberdade, expandir a capacidade de percepçrão de nossos sentidos e compreender as relações existentes na nature$\mathrm{za}$, bem como aquelas geradas pelos grupamentos humanos. $\mathrm{O}$ conhecimento produzido representa um patrimônio da sociedade (p. 17).

Desta forma, encontramos um projeto de capitalismo hegemonizador, não só sobre a vida humana, mas também nas instituições onde é produzido o conhecimento científico. Esse conhecimento pouco tem contribuído para manter e construir o saber científico socializador, tal como Cogiolla (apud TAFFAREL, 2007) comenta.

Muitas mudanças atingiram as Universidades devido às reformas do Estado, dentre elas, a questão que coloca a educação como parte do "Setor de serviços não exclusivos do Estado". Isso resultou em dois pontos apontados por Chauí (2003) e que analisamos aqui: 
1. A educação deixou de ser concebida como um direito e passou a ser considerada um serviço e/ou privilégio;

2. A educação deixou de ser considerada como um serviço público para um serviço que pode ser privado ou privatizado, e não sendo apenas isso, a Universidade deixou de ser uma instituição social para ser uma organização social.

Para Chauí, uma organização social diferencia-se de uma instituição social por trabalhar com eficácia, com competitividade, que tem a si mesma como referência num processo de competição com outras que também fixaram os mesmos objetivos de interesse privado. Diferentemente, uma instituição social tem toda a sociedade como seu princípio e sua referência normativa e valorativa. Em linhas gerais, a organização social tem como objetivo, atender as exigências do mercado capitalista, enquanto a instituição social busca atender a demanda da sociedade a partir da formação humana autônoma, auto-determinada, e emancipada. Atrelada a Universidade, vista como organização social, o interesse crítico e reflexivo que orienta a pesquisa, ou poderia orientar, é deixado de lado, dando lugar a produção científica com objetivo principal, muitas vezes, direcionado a atender interesses de instituições privadas. Sendo por elas financiada, a pesquisa apresenta resultados que expressam os interesses privados em detrimento do interesse público, e argumentam sua relevância, a partir do desenvolvimento econômico privado como possibilidade para "equidade social".

Essa contradição entre Universidade/ instituição social e Universidade/ organização social contribui para fomentar pesquisas que favorecem a dificuldade de enfrentamento crítico às propostas científicas resultantes de parcerias público-privadas. A justificativa desse projeto de pesquisa está voltada a atender o desenvolvimento social a partir do desenvolvimento econômico privado. A ambigüidade da Universidade organização/ instituição enfraquece a capacidade de discernimento entre as pesquisas que atendem demandas sociais e as de interesse privado, gerando uma instituição coerente com a lógica de funcionamento do capitalismo, ou seja, desenvolver o meio de produção da propriedade privada para gerar a riqueza econômica que garanta automaticamente a equidade social. Nesse sistema aparentemente aporético, é valorizada uma ciência efêmera, fragmentada, em demasiada quantidade para se manter ativo, pertencente e não excluído pelo próprio sistema.

Assim como Silva (2005) enfatiza, a lógica da produção acadêmica é fruto do sistema capitalista 
vigente, na qual a estrutura da sociedade competitiva não admite perdedores, apenas vencedores. A ciência deixa de ser um constructo refletido a partir de uma real lacuna da humanidade para se tornar a medida de sucesso, refletida publicamente e explicitamente no currículo Lattes. Não importa o caminho ou o percurso para chegar à determinada descoberta ou contribuição científica, o que importa é a quantidade de publicações que se consegue em um currículo. O currículo Lattes, por sua vez, é um bom meio de organizar e divulgar internacionalmente on line as produções. Associada a essa característica de publicidade dos dados, a tabela do "Qualis" ${ }^{6 "}$ da Capes, faz dele instrumento que indicará quão bom o profissional é, em determinada área, pela qualidade de seus trabalhos (medidos pelo "Qualis" da Capes) e também pelo número de publicações produzidas, expressando uma ciência quantitativa, seja pelo número total de trabalhos produzidos, seja pela classificação de qualidade da Capes.
O citado acima reflete em como muitos pesquisadores, ao correrem contra o tempo, na busca de um lattes mais "recheado", tornamse seres extremamente produtivos, com as mais diversas intenções, tanto no sentido de obter status como até mesmo para se manter credenciado em algum programa e continuar pesquisando. Muitos pesquisadores, ao se submeterem a tal processo que a própria Capes enfatiza, deixam de viver para publicar, ou então, publicam para viver, ou mais ainda, não suportam o nível de exigências e adoecem, permitindo-se fazer parte do "publique ou morra", bem discutido em Evangelista (2006).

Bianchetti (2005) argumenta que anteriormente, ainda não rodeado pelo neoliberalismo, o currículo era um preparo profissional e as atividades descritas demonstravam seu percurso ao longo da vida. Hoje, principalmente no âmbito acadêmico, a busca por um currículo lattes grande não é sinal de percurso, mas sinal de uma pontuação para chegar a um topo maior.

6 Qualis é o conjunto de procedimentos utilizados pela Capes para estratificação da qualidade da produção intelectual dos programas de pós-graduação. Tal processo foi concebido para atender as necessidades específicas do sistema de avaliação e é baseado nas informações fornecidas por meio do aplicativo Coleta de Dados. Como resultado, disponibiliza uma lista com a classificação dos veículos utilizados pelos programas de pós-graduação para a divulgação da sua produção. A estratificação da qualidade dessa produção é realizada de forma indireta. Dessa forma, o Qualis afere a qualidade dos artigos e de outros tipos de produção, a partir da análise da qualidade dos veículos de divulgação, ou seja, periódicos científicos e anais de eventos. 
No caso da Educação Físi$\mathrm{ca}$, o retrato parece ser ainda pior. No que diz respeito a publicações em periódicos, foi feita análise da tabela da Capes atualizada em 2009. Dentre os periódicos da Educação Física, existem aproximadamente 63 classificados na categoria A1, todos ligados à área Médica, Biológica e Esportiva, esta última com ênfase em pesquisas de eficiência e desempenho humano. As pesquisas desenvolvidas na área de humanas, por exemplo, prática pedagógica, filosofia, ciências sociais, não teriam possibilidades de publicar artigos em periódicos $\mathrm{A} 1$ da área da Educação Física (área 21). Esta impossibilidade dificulta o desenvolvimento de pesquisas sobre tais temáticas no âmbito acadêmico da Educação Física, pois todos os pesquisadores, sejam eles professores ou estudantes, devem submeter-se a uma avaliação periódica na qual a sua produção é enquadrada na classificação apresentada pela Capes. Como nenhum periódico em nível A1 permite a publicação de trabaIhos da área das ciências humanas, os pesquisadores apresentam pontuação baixa para se manter como pesquisadores da Educação Física. Em geral, esta lógica está paulatinamente mostrando a desigualdade de condições para manter pesquisas nas chamadas áreas médicas e as ciências humanas, configurando uma estrutura que dificulta a livre opção por temáticas na produção científica da Educação Física.

Este é apenas o caso da problemática em torno dos periódicos e da Educação Física, mas nesta lógica, a sociedade do conhecimento, longe de indicar uma possibilidade de avanço e crescimento das Universidades, indica a produção de conhecimento destinada ao aumento da informação para o capital financeiro, submetendo-se à sua necessidade, de expandir o conhecimento de forma rápida e superficial. Não é por acaso que as Universidades estão cada vez mais diminuindo a carga horária, os mestrados e doutorados estão deixando de exigir dissertação ou tese e oferecendo a possibilidade de apresentar artigos publicados em periódicos com conceito superior (a saber: A1, A2, B1, B2 e B3) classificados pela Capes. Tudo isso corroborando com o sistema de que pesquisadores que publicam artigos científicos merecem respeito acadêmico, devido ao fato de terem sido aceitos em periódicos "aparentemente" qualificados pelas áreas, o que não necessariamente representa resultados de pesquisas com profundidade teórico-metodológicas e que respondam à demanda social.

A produção de conhecimento, que agora ousamos chamar 
de "produção de informação" se aglomera cada vez mais nos bancos universitários atendendo apenas a lógica capitalista, refletida na competitividade acadêmica e distanciando-se do campo das ciências humanas, como da Educação. Ou seja, as pesquisas na Educação Física, pelo menos as que estão vinculadas a programas de pós-graduação específicos em Educação Física, se distanciam de temáticas sociais, como as pesquisas que buscam analisar o mundo do trabalho pedagógico a partir da produção científica fundamentada nas ciências humanas. Construir pesquisas que se propõem a transformar o espaço pedagógico em sujeitos capazes de solucionar seus problemas e transformar a sociedade perece ser mais difícil na área da Educação Física diante da lógica de uma Universidade ambígua e atrelada em avaliações periódicas de qualidades pré-estabelecidas pelos órgãos de fomento.

Por outro lado, identificamos outra problemática sobre a produção de pesquisa social na Educação Física. Ao realizar uma revisão entre os últimos Anais do CONBRACE, verificamos que o GTT (Grupo de Trabalho Temático) de Escola vem apresentando diversas pesquisas resultantes da prática pedagógica, por outro lado, percebemos também um distanciamento da produção deste GTT com as demais temáticas debatidas neste mesmo evento. Portanto, a escola vem sido valorizada como tema para pesquisas científicas, mas ao mesmo tempo esse conhecimento produzido não está acessível aos professores, assim como, também não atende às necessidades da realidade escolar, do professor e do estudante. A linguagem rebuscada e abstrata, associada à dificuldade de acessos, dificulta a compreensão de toda a comunidade escolar, desestimulando o acesso e a produção do conhecimento.

Gamboa (2007) argumenta que muitas pesquisas realizadas nas Universidades cumprem exclusivamente um papel de requisito para obtenção de titulação, pouco são aquelas que demonstram interesse em aplicar os resultados à problemática estudada e sobre aquelas que envolvem a realidade educativa, a sua grande maioria pouco ou nada contribui para transformá-la ou chegar aos cuidados dos professores e gestores escolares.

Como comentado anteriormente, podemos considerar a distância entre pesquisa e ação educativa que tem a realidade escolar como

7 Informação fragmentada e com pouca profundidade teórico-metodológica como os famosos "papers" e os modelos alternativos de defesas de dissertação e tese. 
resultado de um sistema que não privilegia a qualidade da pesquisa ou a sua relevância enquanto a ação transformadora. Essa mesma distância vem atingindo um dos maiores campos de trabalho da Educação Física, as escolas, desprivilegiando a pesquisa qualitativa e privilegiando a produção efêmera, muitas vezes destinada apenas a manter pontuação nos currículos ou em busca de uma determinada titulação, principalmente para enquadrar-se ao sistema.

Com a lógica atual, impactando a Universidade brasileira, a relação da pesquisa com o retorno à sociedade, e no nosso caso em questão, o retorno à escola, torna-se distanciada, enquanto deveria propor intervenções à realidade escolar estudada. Gamboa (2007) argumenta que um projeto de pesquisa para propor uma intervenção escolar, é necessário um diagnóstico exaustivo e rigoroso a partir de uma problemática, para que esta intervenção seja de relevância, o que de fato não vem ocorrendo nas pesquisas acadêmicas das Pós-graduações do Brasil. Para complemento:

\section{(...) Podemos deduzir que a} possibilidade que um estudo tem de oferecer considerações e estratégias de aplicação e definição da qualidade da ação sugerida depende do tipo e grau de interesse crítico que orienta a pesquisa e, por sua vez, do tipo, volume e extensão das informações recolhidas (GAMBOA, 2007, p. 113).

Este contexto coloca algumas Instituições Universitárias de formação e Investigação perante um agudo e crítico desafio: o de corresponderem às exigências de relevância e utilidade impostas pela sociedade, porém sem perderem a tradição e respeito conquistado enquanto produtora do saber social.

Os professores de escola, por exemplo, são, muitas das vezes, usados como objetos de pesquisas acadêmicas, mas poucos são aqueles que participam, constroem conhecimento junto ao pesquisador, ou seja, poucos são pesquisas que permitem a participação deles enquanto sujeitos. São construídas teorias para uma prática escolar, mas poucas vezes essa teoria chega aos mediadores dessa prática, os professores. Esquecemos muitas vezes que uma prática é sempre uma prática de uma teoria, e esta última, é re-elaborada a partir da prática, e, uma vez analisada e compreendida, deve voltar sobre esta em forma de estratégias de ação (GAMBOA, 2007). Dessa forma, questionamos criticamente se é essa a lógica que queremos para a nossa sociedade.

Podemos pensar que as mídias podem favorecer a democratização do conhecimento para 
todos, inclusive para os professores que se encontram atuando apenas na prática escolar. Ora, precisamos refletir que democratização é essa? E que de acordo com os argumentos sobre a produção e o mundo do trabalho pedagógico, podemos considerá-la, atualmente, como uma pseudo-democratização. A democratização não pode ser considerada por causa da amplitude das oportunidades de acesso aos produtos simbólicos no capitalismo contemporâneo, pois é este o ideal, a difusão da informação através das mídias, informação esta caracterizada pela agilidade capitalista. Analisando radicalmente, apontamos a existência de apenas uma lógica: acentuar as exigências do neoliberalismo, a desqualificação dos trabalhadores no processo de qualificação acadêmica, sendo-nos imposta cada vez mais a forma de sociedade evidentemente capitalista, que não busca o conhecimento profundo dos conteúdos clássicos, mas apenas a difusão veloz e fragmentada da informação, unida a isso, pouco se interessa se o conhecimento chega à Escola ou não.

Cria-se uma falsa democratização do conhecimento que se torna informativo, de acordo com o pensamento de Bianchetti (2005):

(...) A transformação dos meios de comunicação em artefatos democratizados - no sentido de que todos possam ter acesso a eles - e democratizadores pelo uso que deles se fizer, no sentido de transformá-los em meios de articulação da esfera pública e radicalização democrática, poderia criar uma realidade bem diferente daquela que acabou se concretizando, onde alguns produzem, discutem e outros consomem informações. (p. 178).

\section{Considerações finais}

O conhecimento produzido, longe de indicar uma possibilidade de grande avanço e desenvolvimento autônomo das Universidades, torna-se cada vez mais distantes do mundo do trabalho pedagógico, especificamente, a escola, pois sua realização não chega até ela. Assim como Gamboa (2007) enfatiza, o conhecimento parte da prática, mas não volta sobre ela mesma, e assim deixa de estabelecer um critério de verdade que exige uma tensão dialética entre esses dois pólos. Assim, o conhecimento torna-se destinado ao aumento de informações para o capitalismo, submetendo-se às suas necessidades (que não necessariamente são as necessidades da realidade escolar), sua lógica. Suas pesquisas são autonomamente definidas ou se destinam parcialmente a busca de respostas que contemplem 
as demandas sociais e políticas de sua sociedade. Esta é a lógica da sociedade do conhecimento, que ousamos chamar da sociedade da informação. Com isso, perde-se a principal meta do trabalho universitário: a formação crítica e reflexiva.

Não podemos perder o sentido da formação se quisermos uma Universidade pública não movida pelo capital, ou seja, concordando com Chauí (2003), sobre a importância de valorizar a Universidade enquanto uma instituição social. O Estado precisa reconhecer a educação como um investimento social e político, o qual somente se dará caso a Universidade seja considerada um direito e não um privilégio ou serviço.

De acordo com Taffarel (2007), os fatos demonstram a tese de que a ciência não é neutra e que a cooptação para construção dos consensos na lógica do capital significa um retrocesso na luta histórica pela superação do capitalismo. Afirma ela que a tendência dos cientistas à fragmentação reflete a própria tendência da fragmentação da produção, para o crescimento desordenado da divisão social capitalista do trabalho.

Isto não significa a emancipação da ciência em relação à filosofia, mas sua colocação a serviço da pior filosofia, sua submissão às idéias dominantes de uma época, às idéias da classe dominante. Tudo isso abordado até o momento foi imprescindível para a compreensão do fenômeno.

Assim finalizamos ressaltando que se faz necessário por parte dos pesquisadores, assumirem uma defesa de política científica e articular o conhecimento entre Escola/Graduação/Pós-Graduação/ Sociedade. Somente assim estaremos à busca de caminhos alternativos para reverter à atual situação, incentivando-nos a em especial agir em prol da Educação e da Sociedade como um todo.

\section{Referências}

B I A N CHETTI, Lucídio. Curriculum vitae em tempos de empreendedorismo e empregabilidade. In: AUED, Bernardete W. (Org.). Traços do trabalho coletivo. 1 ed. São Paulo: Casa do Psicólogo, 2005, v. 1, p. 145-197.

BIANCHETTI, Lucídio. 30 Anos do Colégio Brasileiro de Ciências do Esporte: Os desafios para uma associação científica e os dilemas dos intelectuais institucionalizados. Revista Brasileira de Ciências do Esporte. Campinas, v. 30, n. 3, p. 13-30, 2009.

CHAUÍ, Marilena. Ideologia neoliberal e universidade. In: OLIVEIRA, F.; 
PAOLI, M. C. (org.) Os sentidos da democracia: políticas do dissenso e hegemonia global. Petrópolis/ Rio de Janeiro: Vozes; 1999.

CHAUÍ, Marilena. A Universidade pública sob nova perspectiva. Revista Brasileira de Educação, Rio de Janeiro: Anped/Autores Associados, n. 24, p. 5-15, set/ dez 2003.

KATZ, Cláudio; COGGIOLA, Osvaldo. Neoliberalismo ou crise do capital? 2 ed. São Paulo: Xamã, 1996.

EVANGELISTA, Olinda. Publicar ou morrer? In: BIACHETTI, L.; MACHADO, A. M. N. (Orgs.) A bússola do escrever. Desafios $\mathrm{e}$ estratégias na orientação e escrita de teses e dissertações. 2 ed. São Paulo: Cortez, Florianópolis: Editora da UFSC, 2006.

FRIGOTTO, Gaudêncio. Estudo Quatro: Estruturas e Sujeitos e os Fundamentos da Relação Trabalho e Educação In: SAVIANI, D.; LOMBARDI, J. C.; SAFELECE J.
L. (orgs.). Capitalismo, trabalho e educação. Campinas, SP: Autores Associados, HISTEDBR, 2002.

GAMBOA, SilvioSanchez. A pesquisa como estratégia de inovação educativa: as abordagens práticas. In: GAMBOA, S. S. Pesquisa em Educação: métodos e epistemologias. Chapecó: Universitária Argos, 2007.

MÉSZÁROS, István. Para além do capital. Campinas/SP: Boitempo/ Editora da UNICAMP, 2002.

TAFFAREL, Celi Neuza Zulke. Política Científica e produção do conhecimento na educação física/ciência do esporte: a conjuntura, as contradições e as possibilidades de superação. In: CARVALHO, Y. M.; LINHARES, M. A. Política científica e produção do conhecimento em educação física. Goiânia: CBCE, 2007.

Recebido: 30/agosto/2009

Aprovado: 27/outubro/2009 